\title{
Research on the Application of Cooperative Learning in College English Teaching
}

\author{
Yina $\mathrm{He}$ \\ School of Foreign Languages, Huaiyin Institute of Technology, Huaian, China
}

\begin{abstract}
By collecting and sorting out relevant theoretical materials, the author analyzes the current situation of college English teaching, and by selecting experimental classes to demonstrate the obvious progress before and after the adoption of cooperative learning teaching model, the author holds that it is imperative to implement cooperative learning teaching model at the present stage, On this basis, this paper tries to put forward several effective cooperative learning strategies and suggestions, hoping to enlighten the front-line teacher's engagement in college English teaching and researching.
\end{abstract}

Index Terms - cooperative learning, college English, examination- oriented education system, application in teaching

\section{INTRODUCTION}

When China initiated the reform and opening up policy in the late 1970s, English has been gaining accelerating public importance and governmental attention, and its college English education has made great progress. However, under the current college English education system, people are often affected by exam-oriented education, and the phenomenon of dumb English and deaf English is prevalent. Therefore, college English teaching reform is urgent. Since 2011, China began a new round of education reform of college English courses, the teaching theory of cooperative learning is put forward and discussed just conform to the requirements of curriculum reform of college English. It combines the traditional teaching with modern psychology, pays attention to the development of interpersonal cognition, and makes up for the deficiency of traditional classroom teaching to some extent.

The single learning method in traditional teaching makes students' enthusiasm for English learning low and the learning efficiency is very few. It is difficult for students to improve their academic performance substantially, the main performances are in the following aspects:

\section{A. Vocabulary}

English words have always been a big obstacle for students to learn English. If they do not master enough vocabulary, students will not be able to read, write and speak English efficiently, and they will have great obstacles in English listening. If this goes on, it will certainly affect the passion and effect of English learning. Therefore, it can be said that vocabulary is the most basic thing of learning English.

\section{B. Grammar}

The mastery of grammar is also a big difficulty for Chinese students to learn English, this is mainly because there is a big difference between English grammar and Chinese grammar, It is difficult for students to understand, and many difficult points of grammar are easily confused and difficult to remember, students will be afraid of grammar at the sight of it, this will inevitably affect their interest in learning.

\section{Reading}

The improvement of English reading level is related to the practical application of English ability. If you do not have basic reading ability, you will have difficulty understanding English materials, emails, etc., and there will be obstacles in communication too. In the traditional Chinese English teaching, the teaching of English reading is more focused on the exam-oriented level and the cultivation of students' exam-oriented ability, rather than the cultivation of students' reading ability, which also leads to the dull learning of English reading.

\section{Writing}

When talking about the English writing teaching in Our country, the teaching methods are too single, we will usually learn the model essay only, this method is very good for coping with taking exam, but the result is that we all write in the same pattern, with no ideas of our own, such writing has deviated from the purpose of writing teaching, although some students have their own ideas, they still can not write efficiently due to the lack of vocabulary or the lack of grammar knowledge.

All of the above problems are the practical difficulties that Chinese students encounter in learning English, and they are also the problems that English teaching must solve, traditional teaching methods can no longer solve the above 
problems. The introduction of cooperative learning will spark new hope for English teaching and bring a glimmer of vitality and dawn to the current situation.

\section{BACKGROUND}

Cooperative learning is an effective means to rapidly improve the mastery of knowledge through cooperation and mutual assistance in the learning process, this innovative educational teaching concept has become the focus on the content of the education field, relevant scholars and researchers are aiming at a series of researches on this aspect, and some satisfactory results were obtained.

\section{A. Research on Cooperative Learning Abroad}

As early as in the last century, some countries in Europe have carried out in-depth research on education and proposed the method of cooperative learning to break through the limitations of traditional education mode. In the last century, European and American countries have made corresponding researches on cooperative learning model. However, at the beginning, it was only on the theoretical level, and then it was gradually applied to teaching practice, until it was vigorously promoted and used by the American education circle.

Cooperative grouping can make learning more effective, learning should not only involve competition, but also cooperation (Dewey, R.T.1994). Cooperation and competition promote and transform each other. In the process of education, we should not only attach importance to competition, but also encourage cooperation. The field theory proposed that students' initiative should be emphasized in the process of education. If teachers hold the initiative and students only passively accept knowledge, the teaching effect will be unsatisfactory. Appropriate return of the dominant power of learning to students will be conducive to the improvement of students' interest in learning (Lewin, 1998). On the basis of this theory, Dodge carried out further research, He proposed that grouping students into groups to study in a team mode would help improve the learning effect of students, and at the same time, cultivate a certain sense of teamwork and competitive spirit. He formally introduced cooperative mode into Pedagogy, and proposed that teachers and students should strengthen interaction in the teaching process.

\section{B. Research on Cooperative Learning at Home}

The idea of cooperative learning was originally proposed by David Koonts, a famous American educator. This innovative concept was the most substantial teaching theory strategy in the mid-1970s and 1980s. Now all countries in the field of education are deeply aware of its potential functions and actively promote its application in classroom teaching. In recent years, although cooperative learning appears frequently in classroom teaching, its practical application is still very serious, the fundamental reason is that teachers do not really realize the essence of cooperative learning concept and lack of practical application skills, they simply think that as long as the students organize themselves into a team to discuss and analyze problems together, it is cooperative learning, which does not reflect the deep connotation of cooperative learning, nor fully explore students' potential independent learning ability.

At the present stage, cooperative learning has become the main breakthrough and manifestation of the transformation of traditional teaching system into modern teaching system, and it has been frequently used by teachers in classroom teaching of various subjects. This is also an important achievement of China's quality-oriented education reform, and students can learn with individuality in the atmosphere of independent inquiry and cooperation. Although college English has been developing towards the direction of quality-oriented education reform, it is still influenced by the traditional teaching mode and it is rare to create language practice opportunities for students, teachers occupy the main body of the classroom and seldom consider students' individual learning habits, strategies and language needs. This kind of education and teaching mode has been unable to meet the development needs of the times. Therefore, it is very urgent and important to understand the deep connotation of cooperative learning and guide teachers to cultivate the educational and teaching concepts keeping pace with the times.

How to effectively apply cooperative learning strategy to college English teaching reform plays an important role in improving the quality of college English teaching (Zhong, 2013). In her paper, Research on Cooperative Learning Strategies of College English Based on Individual Differences of Students, Wang (2013) points out the uniqueness of cooperative learning mode, that is, it emphasizes equality and mutual cooperation, and it also recognizes that this teaching mode has a very broad development space in college English subject, and there will be many problems in the implementation process, so it needs to put energy into continuous improvement to obtain the ideal effect. The focus of cooperative learning is the cultivation of learners' self-learning initiative, cooperative awareness and coordination ability in learning practice, as well as giving play to their own advantages, activating classroom atmosphere and improving learning efficiency (Wang, 2011). In cooperative learning, there is a relationship of cooperation, mutual assistance, mutual dependence and mutual promotion among learning partners. In class, each group member can evaluate each other internally and also exchange and evaluate each other, so as to promote the formation of cooperative skills and learning skills among cooperative learning members and improve the learning efficiency and effect. College English teachers should not only learn the theoretical knowledge of cooperative learning, but also combine it with practice so as to obtain better verification in the classroom, so as to master the cooperative learning mode that is really suitable for college English education and teaching, and ultimately improve the overall teaching quality (Zhang, 2007). 
In Rescue Strategy of Teachers for Students' Cooperative Learning, Huang (2013) takes Wuxi regional higher vocational colleges as the research object, and focuses on the effective measures of practical application of cooperative learning mode, which also provides valuable operational experience for other teachers.

To sum up, under the continuous and deep influence of China's educational reform, the concept of cooperative learning has been gradually extended to college English classes, but there is still no consensus on how to effectively implement this strategy in practice, Therefore, the research on its theory and practice strategy is of great significance to improve the relevant system.

\section{RESULTS AND DisCUSSION}

In order to further verify the effect of cooperative learning on improving English learning, we apply the method of cooperative learning to actual English teaching classes, and then we put forward the corresponding cooperative learning methods according to the specific situation of teachers and students. At the end of the semester, we will make comprehensive evaluation of English cooperative learning through the students' actual learning results and surveys from other aspects , such as from the learning results, from experts and from the students .

A. Cooperative Learning Can Effectively Improve the Quality of College English Teaching

Students' English final exam scores before and after the experiment are shown in the following table:

\begin{tabular}{llll}
\multicolumn{4}{c}{ COMPARISON OF ACHIEVEMENTS BEFORE AND AFTER COOPERATIVE LEARNING } \\
\hline & Average score & Pass rate $(\%)$ & Excellent rate $(\%)$ \\
\hline No English cooperative learning & 84.10 & 95 & 40 \\
English cooperative learning & 92.17 & 100 & 67.5 \\
\hline
\end{tabular}

As can be seen from the table, by comparing the results before and after the cooperative learning of English, we can easily find out that after the cooperative learning, the overall performance of the students is increased significantly, the average score is increased by nearly 8 points, and all the students passed the exam, this can fully illustrate that English cooperative learning has a great promoting effect on actual English teaching.

\section{B. Cooperative Learning Can Effectively Improve College Students' Oral English Ability}

In order to help students practice their oral English skills, the school often encourages students to participate in various oral English activities, including competitions, exams and English speaking contests. In the past, the experimental classes had average performances on these tests, but after the cooperative learning model, obviously, the test performances of this class are greatly improved compared with those of the class without taking cooperative learning, which also indicates that cooperative learning can help students to carry out effective oral expression practice.

\section{Cooperative Learning Can Improve College Students' Learning Interest, Cooperation and Communication Ability}

This survey is conducted among 42 students from the Social Science Department, class 1171 in a school, and it is based on the results of English learning. For example, it can be carried out from the aspects of mastering the knowledge, their interests and learning methods in English learning, their evaluation and acceptance in the use of cooperative learning, etc.

Through the data analysis after the survey, it can be found that the original students are not interested in learning English, and there are difficulties in understanding, remembering and using the English language. Through cooperative learning, they can deepen their understanding and memory of English words when participate in the actual discussion of English words, And then it is generally believed that learning English is not so difficult as imagined, so the interest in learning English has increased.

A very important step in cooperative learning is group discussion. According to the survey, after group discussion, each student has a sense of mission and responsibility, and the discussion results of each student will affect the group's performance, therefore, they will actively participate in the discussion and constantly learn from the experience of other students, which not only enhances the memory of the students themselves, but also strengthens the cooperation among the students.

Through the survey, students hope that teachers can adopt this method in their future English learning and their attitude towards English cooperative learning is also changing day to day after taking this learning method. In this way, students can not only master the knowledge in books, but also have a strong interest in learning English, this fully demonstrates that English cooperative learning has produced an effect in the actual teaching process and effectively improved students' English ability.

\section{REFLECTIONS}

Any attempt of a new teaching method cannot be smooth sailing. There are also some problems that cannot be ignored in the implementation of group cooperative teaching in college English teaching. 
We can not simply divide the students into several groups in Cooperative learning. We should not only let the group learning stay in the superficial form, but also pay attention to many deep issues in the specific teaching process. If students are assigned to make an English courseware related to the teaching topic according to Five Famous Symbols of Chinese Culture, it is necessary to supervise the participation of students in the production process, specify the division of labor, and ensure that each member of the group can participate and give full play to their own strengths. Some students are responsible for collecting pictures, texts, video and audio materials, some students are responsible for editing, and the final presentation. We must ensure and supervise that every student works hard for this learning task, so as to improve students' participation and enthusiasm in English learning. If we only assign a cooperative task from the form, and do not give full play to the advantages of group cooperation, the learning results cannot fully represent the level of the group. The reason is that the students' self-management ability is poor, and they haven't formed the consciousness and ability of cooperative learning. The teachers haven't timely reminded and guided the students in each group to discuss and communicate with each other.

\section{B. Student Participation Is Uneven}

Group learning does increase the opportunities for students to participate, However, students who have a better mastery of the English language will usually have more opportunities to participate and often play a helpful role. Students whose English are not so good will become listeners and often get information directly from the top students without the opportunity to think independently. As a result, poor students benefit less from group cooperative learning than from the usual class teaching. One of the main reasons for this situation is that teachers will usually focus on the results of group learning only, rather than on the learning process and individual learning situation; The second reason is that the group leader did not manage the group activities well, and those students who will sneak off easily are usually lack of the sense of collective responsibility.

\section{Cooperation among Students Is Not Active Enough}

In the process of group cooperative learning, students should form a good relationship of mutual help and interaction, however, in group activities, the phenomenon of not being friendly, not listening and not sharing often occurs, which will affect the smooth development of cooperative learning, nowadays most students are only children, some of them are selfish and independent, which is the main reason for the above problems.

\section{Value and Reward the Whole over the Individual}

When we study group cooperative learning, we think that group cooperative learning takes the performance of the group as the evaluation standard, which is undoubtedly correct, but it may lead the teachers who implement group cooperative learning to the misunderstanding that teachers tend to place too much value and reward on the group as a whole and neglect individual development, this is also not useful for a successful cooperative learning.

\section{E. Abuse of Group Cooperative Learning}

Group cooperative learning is a kind of learning method advocated by the new curriculum, however, in the eyes of many people, it has become the symbol of the new curriculum. It seems that it cannot be called the new curriculum without this. Therefore, it is widely used in classroom teaching of various subjects, regardless of whether such cooperation is really necessary or beneficial to improve classroom teaching efficiency, the main reason for this phenomenon is that teachers lack a comprehensive understanding of the nature of the new curriculum.

\section{SugGestions}

\section{A. For Teachers}

First of all, teachers should not only have good psychological quality, but also improve their teaching ability through continuous learning. It is necessary to understand the psychological state of students and deal with the problems in cooperative learning teaching flexibly. Before using the cooperative learning teaching model, they should not only master the current research results at home and abroad, but also choose the appropriate method according to the national conditions and the actual educational level of our country; They should not only to be familiar with the teaching content, but also to understand the learning ability of students learning situation, find problems, to actively summarize, and seek solutions; Teachers should also strengthen exchanges, learn from each other and learn from each other's successful teaching experience.

Second, the basis of cooperative learning is to divide students into small teams, which is not an easy thing. Only on the basis of having a basic understanding of the whole class's learning level, learning ability and even personality, can a teacher make a reasonable arrangement. In the cooperative learning of college English, scientific and reasonable grouping should be carried out first. When grouping, make sure the overall differences between the different groups are small, and at the same time, it is also necessary to ensure the balance of students' learning ability in English reading within each group. Small differences between groups require that students with equal learning abilities be averaged among groups before they are grouped, while the balance between the group and other groups requires that the students in the group and other groups average their reading ability, comprehension ability and generalization ability. Only in 
this way can each group achieve the same task, so that each group member can complete the assigned learning task, and then can communicate and assist each other.

Third, according to the relevant requirements of the new curriculum reform, education should be student-led, and the initiative of learning and the dominant power of class should be given to students, especially for college students with strong self-consciousness and mature cognitive ability who have formed their own values. When designing teaching programs, students' actual conditions should also be fully considered. No matter it is group cooperation or other modes, students' acceptance ability and learning effect should be the evaluation standard, and teachers should strengthen the dialogue and communication with students.

The last, interest is the source of motivation for students to learn. Teachers should try to cultivate students' interest in learning English, especially in cooperative learning. If it is difficult to learn, they should adopt traditional teaching methods, if the cooperative learning teaching mode is still adopted without considering about the special situation, it is easy for students to lose interest in learning due to difficulty. For the topics and contents that students are interested in, teachers can actively adopt the teaching mode of cooperative learning without hesitation.

\section{B. For Students}

Firstly, due to the limitation of geographical conditions, every university will have students from all over the country. For some students from remote areas and rural areas, their English pronunciation is obviously with local accent, plus by exam-oriented education, the former middle school learning English is to do papers, exercises, although their English vocabulary is large, and they have a good grasp of grammar, but the practice of oral opportunities are few and far between, this kind of dumb English phenomenon has continued to the university stage. All these are not conducive to the development of college English cooperative learning model, not conducive to the improvement of college students' English level.

Secondly, students are the principal part of learning, they should give full play to their subjective initiative and active learning so as to achieve good learning results. In the process of group discussion, students should speak up actively, bravely express their own views and opinions, rationally communicate and discuss with the members of the group, and be in a correct state of mind, be good at listening and absorbing different opinions and opinions. When assigning tasks to groups, they should obey the management and arrangement and actively participate in group learning activities.

\section{For Teaching Process}

Whether cooperative learning teaching mode can be carried out smoothly is a dynamic process. Only by adjusting and correcting problems in time can we ensure that this teaching mode is not mere formality. This dynamic process is mainly manifested in the following three aspects: First of all, reasonable selection of English teaching materials. Teachers should first have a comprehensive understanding of the content of teaching, conduct corresponding teaching analysis, classify the key points and difficulties, and then decide whether to take it as the content of cooperative learning according to the corresponding standards; Secondly, teachers should first have a comprehensive understanding of the content of teaching, conduct corresponding teaching analysis, classify the key points and difficulties, and then decide whether to take it as the content of cooperative learning according to the corresponding standards; Thirdly, the evaluation and reward of cooperative learning should be positive and pertinent. On the one hand, the evaluation of cooperative learning is conducive to discovering the problems existing in practical cooperative learning and helping teachers to improve the methods and methods of cooperative learning, on the other hand, evaluating cooperative learning from the perspective of students can help to develop deeper cooperative learning among students, effectively inspire and motivate students, cultivate students' deep interest in learning English and cultivate the spirit of mutual help, friendship, solidarity and upward with other students.

\section{For Teaching Environment}

Colleges and universities should pay attention to students' English learning, realize that the traditional teaching mode can not meet the needs of current college English teaching, and actively adopt new teaching modes such as cooperative learning to better achieve the teaching objectives. The school should provide support for the development of cooperative learning model in English teaching. At the same time, relevant training courses should be provided for teachers to improve their ability and level of teaching in this mode, encourage teachers to learn from each other, and organize exchanges and cooperation between colleges and universities in the sharing learning mode when necessary.

\section{CONCLUSION}

Under the continuous and in-depth influence of China's educational reform, the concept of cooperative learning has been gradually extended to college English classes. However, there is still no consensus on how to effectively implement this strategy in practice, therefore, after collecting and sorting out relevant theoretical materials, the author expounds the research background of college English cooperative learning, analyzes the problems that may exist in the implementation of cooperative learning strategies in colleges and universities and the related factors that cause the problems, and tries to put forward several effective cooperative learning strategies and suggestions, has a discussion on how to carry out college English teaching reform under the new situation and improve college students' English 
communicative competence by using effective cooperative learning methods. At the same time, they should strengthen their independent learning ability, cultivate their sense of cooperation and improve their comprehensive cultural quality to meet the needs of China's social development and international exchanges. It is hoped that the research results of this paper can be used to enrich the existing theoretical system, and meanwhile, it will have some enlightening significance for front-line teachers engaged in college English teaching and research.

\section{REFERENCES}

[1] Dewey, R.T. (1994). Second Language Acquisition. England: Cambridge University Press.

[2] David Lewin. (1998). Designing Tasks for the Communicative Classroom. England: Cambridge University Press.

[3] Vermett, Dodge. (1998). Making Cooperative Work. New Jersey, Merrill. Language Learning, 46, 101-135.

[4] Zhong Dongcai. (2013). The Effect of Cooperative Learning on Relieving English Classroom Anxiety of Students with Learning Difficulties. Harbin Normal University, 27, 249-250.

[5] Wang Jiaxin. (2013). Research on Cooperative Learning Strategies of College English Based on Individual Differences of Students, Journal of Sichuan Teachers College (Philosophy and Social Sciences), 2, 101-106.

[6] Wang Wei. (2011). College English Classroom Teaching Design Based on Group Cooperative Learning. Foreign Language World, 3, 54-61.

[7] Huang Huili. (2013). The Strategies of Teachers' Assistance to Students' Cooperative Learning. Shandong Foreign Language Teaching Journal, 2, 60-63.

[8] ZhangHaiyan. (2007). Research on teachers'cooperative learning concept and cooperative learning implementation. Teaching Research, 4, 349-352.

Yina He was born in Shaanxi, China in 1981. She received her master's degree in Science Education from Henan University, China in 2017. She is currently a lecturer in the School of Foreign Languages, Huaiyin Institute of Technology, Huaian,China. Her research interests include Second Language, teaching method, intercultural communication. 